\title{
TRIBUNA
}

\section{Orígenes, historia y valores de ETEA, una institución universitaria de la Compañía de Jesús}

\section{Lección inaugural (27 de septiembre de 20I2)}

\author{
Jaime LoRing Miró S. I.
}

\begin{abstract}
En 1963 los jesuitas comenzaron en Córdoba una nueva obra, una escuela de formación de empresarios agrícolas, obra de colaboración social en la que participó la familia López Giménez. ETEA nació con la voluntad de ser un centro de formación superior, universitaria, al modo de las escuelas de formación de empresarios que a finales de la década anterior y en aquellos años la Compañía de Jesús había puesto en marcha en bastantes ciudades españolas (Alicante, Barcelona, Bilbao, Madrid, Santander, Valladolid). El precedente inmediato lo constituyeron el centro universitario de estudios empresariales de San Sebastián, así como los de estudios comerciales de Deusto (Bilbao) y de Barcelona. Como primer director de ETEA, Jaime Loring puede ser considerado no sólo su fundador, sino su inspirador $y$ orientador durante muchos años de ejercicio profesional (directivo, docente e investigador) y compromiso apostólico en esta institución universitaria jesuita cordobesa. Al comenzar el año cincuentenario de la fundación el profesor Loring ha sido encargado de pronunciar la lección inaugural del curso que reproducimos a continuación.
\end{abstract}

Comenzamos este año el último curso escolar en que ETEA tiene la figura jurídica de una institución académica independiente. El próximo mes de octubre 2013 la Universidad Loyola Andalucía iniciará su actividad. ETEA pasará a ser una Facultad, entre otras, de esa Universidad. ETEA dejará de ser un todo en sí mismo para convertirse en parte de un conjunto más amplio. Si se me permite una comparación, me atrevería a decir que este año escolar va tener lugar la muerte y la resurrección de ETEA. Termina lo que ETEA ha sido a lo largo de estos 49 años, y renace con una nueva figura transformada, la Universidad Loyola Andalucía. La Universidad Loyola Andalucía no hubiera nacido sin la existencia previa de ETEA. A su vez el inicio de esta nueva Universidad absorbe a ETEA, y la transforma. 
Siguiendo con la misma comparación de la muerte y la resurrección, la absorción de ETEA por la Universidad Loyola, lleva consigo la extinción de la corporeidad de ETEA. Dejarán de tener vigor sus estatutos, sus órganos de gobierno, el uso y destino de sus instalaciones, la estructura laboral de su personal. En cambio permanecerá en vigor lo que pudiéramos llamar el espíritu de ETEA. Los valores que durante estos 49 años han estado vigentes en ETEA, que han configurado su personalidad institucional, $y$ han determinado la imagen social proyectada hacia su entorno.

\section{Los orígenes de ETEA}

\section{I.I. La fundación de ETEA}

La Escuela Superior de Técnica Empresarial Agrícola (ETEA) comenzó su actividad en Córdoba el 2 de octubre de 1963. Su creación fue el resultado de la conjunción de tres circunstancias convergentes.

A finales de la década de 1950 se estaba produciendo en España el paso de la llamada agricultura tradicional a la agricultura empresarial con la intensificación de los regadíos, la mecanización de la agricultura, y la asunción por las empresas agrarias de técnicas modernas de gestión empresarial.

En segundo lugar, un grupo de estudiantes jesuitas que estábamos finalizando los estudios de Teología en la Facultad de Granada, concebimos el proyecto de crear en Andalucía una institución de estudio e investigación sobre la problemática social y económica de Andalucía. La situación social y económica de Andalucía en los años 50 era lamentablemente, lacerante. Nuestro proyecto iba en la línea de un trabajo intelectual y de pensamiento. La forma concreta de llevarlo a cabo no la teníamos definida. Podía ser un centro de investigación y publicaciones, un centro de formación y enseñanza, simplemente una red de estudiosos distribuidos geográficamente.

La tercera circunstancia, dolorosa por cierto, fue el fallecimiento de Rafael Luis López Jiménez, hijo de D. Lorenzo López Cubero. El impacto de este fallecimiento en la familia López Cubero fue muy grande. D. Lorenzo se dirigió al Provincial de los jesuitas en Andalucía, que era por entonces el P. José Antonio de Sobrino, y le ofreció una aportación económica importante, para que los jesuitas creasen 
una institución educativa y social al servicio del desarrollo del mundo agrario de Andalucía, en memoria de su hijo Rafael Luis, recientemente fallecido

Estas tres circunstancias convergieron en la fundación de ETEA en Córdoba.

El P. Sobrino pensó entonces coordinar la oferta de D. Lorenzo, con la iniciativa de aquel grupo de estudiantes jesuitas. Así fue como nos encargó que iniciásemos en Córdoba lo que eran nuestros proyectos estudiantiles, coordinándolos con el deseo de la familia. El encargo que recibimos no estaba definido ni concretado. La definición y concreción del proyecto fue la primera tarea que hubo que hacer. Se tardó aproximadamente un año en tomar la decisión. Finalmente se optó por el modelo de otras instituciones universitarias que por aquellos años habían creado los jesuitas en distintas ciudades españolas: el Instituto Católico de Administración y Dirección de Empresas (ICADE) en Madrid, la Escuela Superior de Administración y Dirección de Empresas (ESADE) en Barcelona, y la Escuela Superior de Técnica Empresarial (ESTE) en San Sebastián. Todas estas instituciones habían ido naciendo a partir de 1956. Nosotros nos decidimos por esta opción sumándonos a la implantación en España de la carrera universitaria de Ciencias Empresariales. En aquellas fechas la universidad estatal española disponía de una Facultad de Ciencias Económicas, pero la carrera de Ciencias Empresariales no existía en el catálogo estatal de títulos universitarios. Nuestra originalidad fue especializar las Ciencias Empresariales en el ámbito de la empresa agraria. Así es como nació la Escuela Superior de Técnica Empresarial Agrícola (ETEA).

Para dar una explicación de la razón histórica que motivó la fundación de ETEA en octubre de 1963 hemos de referirnos a un doble entorno de España en los años 50 , el económico y el académico.

En el ámbito económico la política de modernización agraria impulsada por el Ministro Rafael Cavestany de Anduaga (1902-1958), quien ocupó el Ministerio de Agricultura de 1951 a 1957 (18 de julio 1951).

En el ámbito académico la creación, durante esos años 50, de las tres Escuelas superiores de dirección de empresas mencionadas, que introdujeron en España el modelo de las escuelas de negocios estadounidenses. 


\section{I.2. El ámbito económico: la agricultura andaluza en los 50}

El cambio hacia una agricultura moderna y empresarial tiene lugar durante la década de los 50. El Ministro Cavestany desarrolla una política que posibilitara el aumento del consumo agroalimentario y un nivel mínimo de satisfacción de las necesidades más elementales de la población. El objetivo prioritario era, pues, incrementar la capacidad productiva del sector mediante la modernización técnica de la agricultura.

España salía en esos años de la década de los 40 , años de la postguerra civil. Fueron años dominados por escasez de productos agropecuarios, y consecuentemente el problema generalizado del hambre. Las cartillas de racionamiento y el mercado negro de productos agrarios, conocido como el estraperlo, son características que definen el escenario económico de la agricultura española de los años 40 . Gracias a los acuerdos Franco-Perón se logró un equilbrio significativo en el aprovisionamiento de la población con los cereales procedentes de Argentina. La política agraria de Cavestany estuvo orientada a resolver esta problemática escasez.

Entre las iniciativas promovidas por Cavestany podemos citar la impulsión de los regadíos a través del Instituto Nacional de Colonización y la concentración parcelaria.

\section{I.2.I. El impulso al Instituto Nacional de Colonización}

El Instituto Nacional de Colonización ejecuta entre otros el Plan Badajoz que se aprueba por Ley de 7 de abril de $1952^{1}$ y el Plan Jaén aprobado mediante Ley el 17 de julio de 19532,

Cavestany impulsó la política estatal de regadío, confiriéndole un vigor hasta entonces desconocido. El riego era, en su opinión, la solución para los problemas productivos y sociales del campo español, por lo que la política de ampliación del regadío se planteaba con el único límite de los recursos hídricos disponibles. En consonancia con tales propósitos, a partir de los años cincuenta se produjo un fuerte desarrollo en la construcción de obras hidráulicas, especialmente embalses y pozos, que sirvieron de soporte a la ampliación del regadío.

${ }^{1}$ BOE (Boletín Oficial del Estado) del 8 de abril de 1952. Aranzadi 1952, n 547

${ }^{2}$ Aranzadi 1953, n 908 
Los planes Badajoz y Jaén fueron la máxima expresión de esta simbiosis entre política de colonización y desarrollo regional. Se trataba de formular planes regionales para impulsar el desarrollo sobre la base de la transformación operada por la realización de obras hidráulicas. El modelo del Plan Badajoz, basado en la corrección del atraso por la vía de los regadíos planificados por el Estado, se extendió a otras zonas que tenían una problemática similar.

\section{I.2.2. La concentración parcelaria}

Simultáneamente con el impulso de los regadíos se lleva a cabo un proceso de concentración parcelaria ${ }^{3}$. La primera disposición sobre concentración parcelaria se promulga el 20 de diciembre de 1952. Es todavía un primer ensayo en manos de una comisión a la que se encomienda que en el plazo de los cinco años siguientes redacte un proyecto definitivo. Durante los años 1953 y 54 se publican numerosas Órdenes Ministeriales y algunos Decretos-Leyes referentes a la aplicación de la Concentración Parcelaria. Por último el 10 de agosto de 1955 se aprueba la Ley de Concentración Parcelaria ${ }^{4}$.

El surgimiento de la política de concentración implicó un cambio en el énfasis de la política agraria de la posguerra, al considerarse que la reducida dimensión de las parcelas frenaba el proceso de modernización de las explotaciones agrarias, y la mejora de su eficiencia. Los fines perseguidos con la concentración parcelaria encajaban con el objetivo de la nueva política agraria, que puede sintetizarse en la frase menos agricultores y mejor agricultura.

\section{I.2.3. Cambios en la empresa agraria en la década de los 50}

Así fue como en la década de 1950 se produce una transformación importante de la agricultura española. Crece de forma importante la producción agraria debido al aumento de los regadíos impulsados por el Instituto Nacional de Colonización. La superficie de riego que era de 1,45 millones de hectáreas en 1950 llega a más de 2 millones en 1960. Un incremento de 550.000 hectáreas, un $40 \%$.

\footnotetext{
${ }^{3}$ Manuel MORENO TORRES, La cocentración parcelaria y el registro de la propiedad (http://www.magrama.gob.es/ministerio/pags/biblioteca/revistas/pdf_reas/r016_02.pdf). Ignacio MARTíNEZ DE BEDOYA, Algo sobre las medidas conservatorias de a concentraciòn parcelaria (http://www.magrama.gob.es/ ministerio/pags/biblioteca/revistas/pdf_reas/r013_03.pdf)

${ }^{4}$ BOE 26 de septiembre de 1955
}

Revista de Fomento Social 67 (2012) 
Durante estos años la producción final agraria paso de 53.000 millones de ptas. a 129.000 millones según los datos del Anuario Estadístico de España de 1965. Ello supone un crecimiento del $143 \%$ en pesetas corrientes, $y$ un $47 \%$ en pesetas constantes según el IPC de 1950 a $1960^{5}$

Este aumento de la producción final coincidió con una disminución importante de la población activa agraria que pasa de 5,3 millones de personas en 1950 a 4,6 millones. Una reducción del 13\%. La disminución de la población activa agraria fue en gran parte consecuencia del éxodo rural.

El éxodo rural, se produjo tanto hacia Europa, como hacia las regiones industrializadas de España. A finales de los 50 y principios de los 60, el despegue de la industrialización de España provoca una fuerte demanda de mano de obra en los núcleos fabriles de Madrid, País Vasco y Barcelona. Así mismo la apertura de nuestras fronteras fomenta la salida de trabajadores a otras naciones europeas. La emigración de asalariados lejos de sus lugares habituales de residencia incide en la agricultura con una subida de los salarios, y la sustitución de mano de obra humana por maquinaria. Prueba de ello fue la evolución creciente del número de máquinas utilizadas en las faenas agrícolas ${ }^{6}$.

Entre 1950 y 1960 el número de tractores, motocultores y cosechadoras de arrastre se multiplica por 4, y el de cosechadoras automotrices se multiplica por 9.

Es en este contexto de modernización de la agricultura ocurrida en los años 50, evolucionando hacia la necesidad de introducir técnicas de gestión empresariales, donde se genera el proyecto de ETEA. Se estaba saliendo de una agricultura consistente en el laboreo de la tierra, sin una mecanización generalizada, se intensificaban los regadíos, y se avanzaba a una ampliación de los mercados agropecuarios. El tradicional concepto de "labrador" empezaba a sustituirse por el de "empresario agrícola".

Desde los años 50 del siglo XX hasta hoy se ha producido una fuerte desagrarización de España. Es necesario remontarse a las macromagnitudes de aquellos años para enmarcar adecuadamente la motivación que indujo a la creación de una

\footnotetext{
${ }^{5}$ José Luis GARCíA RuIz, "La inflación en la Espala del sigloXX: teorías y hechos"; (http://www.revistasice. com/CachePDF/BICE_2667_2332_727A2E7D952EA3620F856035A5B615FB.pdf)

${ }^{6}$ El fracaso de la política agraria del primer franquismo, 1939-1959. Veinte años perdidos para la aaricultura española. (http://www.unizar.es/eueez/cahe/lopezortiz.pdf página 49)
} 
Escuela Superior de Técnica Empresarial Agrícola. En los años 50 la producción agraria representaba algo más del $40 \%$ del Producto Interior Bruto español, y la población activa agraria cerca del $50 \%$ de la población activa total ${ }^{7}$. Actualmente tanto una como otra se sitúan alrededor del $4 \%^{8}$.

ETEA nace con el objetivo de contribuir a la transformación social de España incidiendo precisamente en la trasformación de la agricultura introduciendo en ella criterios y métodos modernos de gestión empresarial. Esta idea es la que recoge el logotipo original de ETEA: la espiga referente a la agricultura, el volante de un tractor referente a su modernización mediante la mecanización, y la gráfica estadística referente a la economía.

\section{I.3. El ámbito académico: las Escuelas Superiores de Administración de Empresas}

El segundo entorno del inicio de ETEA lo define el comienzo de la carrera de Administración de Empresas en España

Al comienzo de la década de los años 50 no existían en España los estudios de Ciencias Empresariales. A título excepcional en Bilbao existía la Universidad Comercial de Deusto fundada en $1916^{\circ}$.

En julio de 1953 la Facultad de Ciencias Políticas y Económicas de la Universidad Complutense de Madrid, que existía desde el año 1943, pasó a denominarse Facultad de Ciencias Políticas, Económicas y Comerciales. Pero no fue hasta principios de los años 70 que esta Facultad se escinde en dos la Facultad de Ciencias Políticas y Sociología y la Facultad de Ciencias Económicas y Empresariales ${ }^{10}$.

A lo largo de los años 50 la iniciativa privada inauguró tres Escuelas Superiores de Ciencias Empresariales. Las tres a iniciativa de la Compañía de Jesús. Las tres

\footnotetext{
7 http://www.catedu.es/geografos/images/Documentos/mundo_rural/03_peso_y_problematica_act_agrarias.pdf

${ }^{8}$ Geografía de España. (http://iesasbgeografia.blogspot.com.es/2011_01_01_archive.html)

9 http://es.wikipedia.org/wiki/Facultad_de_Ciencias_Econ\%C3\%B3micas_y_Empresariales_de_la_ Universidad_de_Deusto,_campus_de_Bilbao\#Historia

$10 \mathrm{http}: / /$ www.ucm.es/centros/webs/fccee/index.php?tp=Nuestra Facultad\&a=centro\&d=2402.php
} 
estaban inspiradas en el modelo de la Universidad Comercial de Deusto, y en las escuelas de negocios de Estados Unidos. En 1956 la Escuela Superior de Técnica Empresarial (ESTE) en San Sebastián. También en 1956 el Instituto Católico de Administración y Dirección de Empresas (ICADE) en Madrid. Por último en 1958 la Escuela Superior de Administración y Dirección de Empresas (ESADE) en Barcelona ${ }^{11}$

Estas tres iniciativas fueron las que inspiraron el proyecto de ETEA, como Escuela Superior de Técnica Empresarial Agrícola. La diferencia característica de ETEA fue su incorporación al proceso de modernización de la agricultura que había impulsado la política agraria de Cavestany. ETEA se crea en 1963

Un año más tarde en 1964 se crea en la Universidad de Sevilla el Instituto Universitario de Ciencias de la Empresa (IUCE), que en 1971 se convierte en la Facultad de Ciencias Económicas y Empresariales ${ }^{12}$.

\subsection{Valoración internacional}

1966. El informe del Banco Internacional de Reconstrucción y Fomento (BIRD) y de la Organización de las Naciones Unidas para la Agricultura y la Alimentación (FAO) con el título de El desarrollo de la Agricultura en España, publicado en 1966 por el Ministerio de Hacienda, recomienda al Gobierno español el modelo de estudios cursados en ETEA. Dice textualmente en su página 125, que para proporcionar adiestramiento y formación de administradores agrícolas en las explotaciones de mayores dimensiones, y para dar orientación a los empresarios de menor escala con respecto a la aplicación de métodos comerciales a la planificación de sus actividades agrícolas,

se necesitaría un número mucho mayor de graduados especializados en las técnicas de administración rural y, por consiguiente recomendamos que las escuelas agrìcolas superiores ofrezcan cursos adecuados, semejantes a los que dicta ahora la Escuela Superior de Técnica Empresarial Agrícola de Córdoba sobre una base experimental.

${ }^{11}$ Historia y presente de los estudios de economía y empresa en España, pp. 71-76 (http://www.uah. es/empresariales/escuela/documentos/libro_blanco/capitulo4.pdf)

12 http://www.comunicacion.us.es/node/6277 


\section{Síntesis histórica de ETEA}

Quisiera hacer ahora una breve reseña histórica de cuáles han sido los cauces por los que ha discurrido la historia de ETEA durante estos 49 años. La voy a dividir en cuatro períodos, a cada uno de los cuales asigno un título:

\begin{tabular}{|c|c|}
\hline Infancia & $1963-1965$ \\
\hline Adolescencia & $1966-1977$ \\
\hline Juventud & $1978-1987$ \\
\hline Madurez & 1988 a la actualidad \\
\hline
\end{tabular}

\section{I. Infancia (1963-1965)}

Comencemos por una primera etapa, que podríamos denominar la infancia de ETEA. Abarca los años 1963, 1964 y 1965, que pasamos en el patio de San Hipólito.

En 1963 se matricularon 18 alumnos, y en 1964, 8 alumnos. A los dos años en total había 26 alumnos, que procedían de toda España: Córdoba, Sevilla, Madrid, Valencia, Canarias, Galicia, Asturias, Barcelona. Éramos 8 o 9 profesores, y una secretaria. En los claustros del patio de San Hipólito se acondicionaron un aula de clase, un despacho de dirección y una pequeña secretaría.

Carecíamos de una estructura física. Incluso la estructura académica era un tanto borrosa. Comenzábamos con el curso A de cinco años, el curso B de tres años, y el curso $C$ con clases solamente vespertinas. En dos o tres años desaparecieron los cursos $B$ y $C$, quedó solamente el curso $A$. Sabíamos entonces lo que queríamos, lo que no sabíamos exactamente era cómo llevarlo a cabo. ETEA tenía un proyecto, lo que no tenía era una planificación. Sabíamos dónde queríamos llegar, lo que no sabíamos todavía era cuál era el camino. El camino hubo que irlo descubriendo cada día a medida que nuevos datos y nuevos hechos iban apareciendo en el horizonte. Como el caminante que se adentra en la selva sin mapas, solo con la brújula. Sabe hacia dónde tiene que avanzar, pero el camino lo tiene que encontrar en cada paso.

En 1964 ETEA fue reconocida por el Ministerio de Educación como Centro privado de Formación Profesional con categoría de estudios universitarios, adscrito a la futura Escuela de Ingenieros Agrónomos de Córdoba. Mientras ésta entraba en funcionamiento quedaba adscrito a la de Madrid ${ }^{13}$.

${ }^{13}$ Orden Ministerial de 1 de diciembre de 1964 (BOE 16-12-1964, n 301, p. 16.796). 


\subsection{Adolescencia (1966-1977)}

En 1966 comienza una etapa de unos 11 años, hasta 1977, que yo llamaría la adolescencia. ETEA pasa por un proceso de autoidentificación. Las decisiones se toman a partir de la experiencia. No hay un abandono del proyecto inicial, sino una concreción del mismo. ETEA empieza a autogobernarse, asumiendo por sí misma la responsabilidad de sus opciones.

Este proceso de autoidentificación está marcado por el desplazamiento desde la especificidad agraria hacia la ciencia del "management".

El desplazamiento desde la especificidad agraria hacia la gestión empresarial fue realizándose poco a poco a la vista de las oportunidades de empleo que encontraban los egresados de ETEA, y de las preferencias manifestadas por los alumnos de nuevo ingreso. A la vuelta de dos o tres reformas del plan de estudios, fueron desapareciendo asignaturas como la Botánica, la Fisiología vegetal y animal, la Química, o la Genética, para ser sustituidas por el Control de Gestión, las Fuentes de Financiación, la Gestión Financiera, la Organización, o la Auditoria.

Sin embargo la agricultura no desapareció de ETEA. Es cierto que en el plan de estudios ya no figuran asignaturas importadas de las carreras de ingeniero agrónomo o de veterinaria. En cambio, la participación de ETEA en trabajos de investigación y asesoramiento en economía agraria, siguió siendo una de nuestras características institucionales. La participación de ETEA en la elaboración de proyectos de desarrollo rural, de estudios de costes y estructura económica de la producción agraria, ha sido siempre reconocida y aceptada tanto por la Administración Pública como por empresas privadas. ETEA, pienso que puede decirse, que es la Facultad de Ciencias Económicas y Empresariales de España con más presencia en el mundo agropecuario y agroalimentario.

En estos años tiene lugar la creación de la Escuela de Mandos Intrermedios (EMI), cuyo primer director fue Enrique Summers. Desde el 5 de marzo de 1968 funcionó la Escuela de Mandos Intermedios (EMI) que conjugó la vocación docente de la Institución con su necesaria dedicación a los sectores sociales con menos oportunidades educativas en el ámbito de la empresa. El año 1982 los estudios impartidos por EMI recibieron el reconocimiento oficial de Formación Profesional. La EMI dejó de impartir cursos en junio de 2000. 


\subsection{Juventud (1978-1987)}

La tercera etapa de la historia de ETEA la podríamos denominar su juventud, y se extiende de 1978 a 1987. Durante estos nueve años se afianza la solidez de la institución. A lo largo de esta etapa se producen cuatro acontecimientos, que por una parte verifican las opciones tomadas en las etapas anteriores, y por otra parte constituyen la base del gran salto cualitativo y cuantitativo que ETEA ha experimentado. Podemos enumerar:

1. La creación del Colegio Universitario.

2. El acuerdo con la Universidad Comillas para la homologación de los cursos $4^{\circ}$ y $5^{\circ}$.

3. La creación de la Escuela Universitaria.

4. El inicio de la cooperación con Centroamérica.

Estos cuatro acontecimientos tienen lugar en tres fechas. 1978 creación del Colegio Universitario, 1981 acuerdo con ICADE de la Universidad Comillas para dar homologación oficial a los cursos de $4^{\circ}$ y $5^{\circ}$ de ETEA, y 1983 la creación de la Escuela Universitaria de Ciencias Empresariales, también en 1983 el inicio de la cooperación con Centroamérica

En el momento de su fundación ETEA ofrecía un título absolutamente privado. Estábamos en la misma línea de actuación que habían seguido durante muchos años la Escuela Superior de Ingenieros del ICAl, el Instituto Químico de Sarriá, la propia Universidad de Deusto, y por supuesto las recientes escuelas de Administración de Empresas, ICADE y ESADE.

Sin embargo esta línea de actuación que pudo ser válida a principios del siglo XX, cuando se crearon el ICAl y la Universidad de Deusto, en la década de los 70 empezó a manifestarse insuficiente. Todos estos centros universitarios que impartían titulaciones totalmente privadas, con el único respaldo académico que le prestaba la propia institución, fueron adaptándose a un estatuto jurídico que les capacitara para impartir títulos universitarios con valor oficial en el Estado.

En el marco legal de los años 70 la figura que estaba admitida era la de "Centro privado adscrito a una Universidad Estatal". Por otra parte, el título impartido había de ser uno de los títulos comprendidos en el catálogo de títulos homologados por el Estado. Estas dos prescripciones legales condujeron a que ETEA se "adscribiera" a la Universidad de Córdoba, primero como Colegio Universitario, y más tarde 
como Facultad de Ciencias Económicas y Empresariales. Esta fue la razón por la que dejó de impartirse el título de Licenciado en Ciencias Empresariales Agrarias, y fue sustituido por el de Licenciado en Ciencias Empresariales. El plan de estudios experimentó gradualmente una transformación eliminando las asignaturas propiamente agronómicas que se impartían en un comienzo para sustituirlas por las asignaturas propias de la nueva titulación. La creación del Colegio Universitario tuvo lugar por Real Decreto de 15 de septiembre de 1978'4. El 1 de febrero de 1979 se firmó el correspondiente convenio entre la Compañía de Jesús y la Universidad de Córdoba. Desde entonces los tres años de carrera del Colegio Universitario sustituyeron a los tres primeros cursos de ETEA.

Todavía quedaban pendientes de tener homologación oficial los cursos $4^{\circ}$ y $5^{\circ}$ de ETEA, puesto que el Colegio Universitario solamente abarcaba los tres primeros años de carrera. Esta deficiencia se pudo solventar mediante un acuerdo con la Universidad Comillas firmado en julio de 1981. En virtud de este acuerdo los alumnos provenientes del Colegio Universitario y matriculados en cuarto y quinto de ETEA eran recibidos como alumnos de la Facultad de Ciencias Empresariales (ICADE) de aquella Universidad. De esta forma se conseguía, al menos de forma provisional, la validez oficial a nivel de Licenciatura de los estudios cursados por los alumnos de ETEA a la espera de poder conseguir la transformación en una Facultad de Ciencias Empresariales, en el marco de la Ley de Reforma Universitaria y de los futuros Estatutos de la Universidad de Córdoba.

En 1983 nace la Escuela Universitaria de Ciencias Empresariales adscrita a la Universidad de Córdoba, que impartiría la Diplomatura en Ciencias Empresariales. Su creación fue motivada por la extinción de las Escuelas Profesionales de Comercio que habrían de integrarse en la Universidad como Escuelas Universitarias, tal como se estableció en la Ley General de educación de 197015. La extinción definitiva de los planes de estudio de Peritaje Mercantil no se hizo hasta el curso 1979-80 en virtud del Real Decreto de 29 de enero de 197916.

En virtud de ambas disposiciones se procede al cierre de la Escuela Pericial de Comercio de Córdoba, que venía funcionando desde el curso 1955-56.

\footnotetext{
${ }^{14}$ Real Decreto 2348/1978 de 15 de septiembre de 1978 (BOE 3-10-1978, n²36, p. 22993)

${ }^{15}$ Ley 14/1970 de 4 de agosto BOE 6-6-1970, Disposición transitoria 10

${ }^{16}$ Real Decreto 265/1979 de 26 de enero BOE 17-02-1979 Extinción de Peritos mercantiles, artículo 21.
} 
El cierre tendría lugar al término de ese año académico, el 30 de septiembre de 1980.

El 24 de septiembre de 1980 la Junta de Gobierno de la Universidad de Córdoba tomó el acuerdo siguiente:

La Junta de Gobierno "a la vista de la extinción de la Escuela Profesional de Comercio y del vacío que esta medida ha creado" considera que estas necesidades de titulados medios en Ciencias Empresariales deben satisfacerse a corto plazo a través del Centro ya existente, el Colegio Universitario de Ciencias Empresariales. A estos efectos el referido Centro deberá realizar las gestiones oportunas para que, tras las debidas convalidaciones y autorización para impartir las asignaturas complementarias necesarias, pueda expedir el correspondiente diploma. La anterior solicitud, tan pronto se produzca, contaría con el apoyo de la Universidad.

El 12 de noviembre de 1980 el Patronato del Colegio Universitario tomó por unanimidad el acuerdo de secundar las indicaciones de la Junta de gobierno de la Universidad, y en virtud de ello solicitar del Ministerio de Universidades la autorización oportuna para impartir la Diplomatura en Ciencias Empresariales. Dicho acuerdo fué trasladado con el informe favorable de la Junta de Gobierno de la Universidad al Ministerio de Universidades por el Rector de la Universidad de Córdoba, Alberto Losada Villasante, el 20 de diciembre de 1980.

Finalmente por Real Decreto de 9 de marzo de $1983^{17}$ se crea la Escuela Universitaria de Ciencias Empresariales adscrita a la Universidad de Córdoba. El convenio correspondiente entre la Compañía de Jesús y la Universidad de Córdoba se firmó el 4 de julio de 1983.

Ese mismo año de 1983 se inicia la colaboración con la Universidad Centroamericana (UCA) de San Salvador y en 1986 con la de Managua. Más tarde en 1996 con la Facultad de Economía de La Habana.

Sin duda alguna estos nueve años que he definido como la juventud han sido los años decisivos. Durante estos nueve años llegó a consumarse el proyecto académico y social de ETEA como institución. El currículum académico adquiría finalmente una configuración sólida. Sociológicamente ETEA pasó de ser un centro cualificado, respetado, pero seamos sinceros, testimonial, a ser un centro con gran peso universitario en Córdoba. A la vez se consiguió la estabilización y saneamiento financiero de la institución.

17 Decreto 1059/1983 de 9 de marzo de 1983 (BOE, 30-04-1983, n 103, pp. 12072-12073) 
Paralelamente se produjo un crecimiento cualitativo importante. Los equipamientos docentes en cuanto a fondos bibliográficos de la biblioteca, salas de lectura, medios didácticos audiovisuales, ordenadores conectados a internet a disposición de los estudiantes, etc., aumentaron, lo que cambió sustancialmente la configuración de ETEA.

\subsection{La madurez (I 988-a la actualidad)}

La última etapa de 1988 a la actualidad la denominaría su etapa de madurez. Durante este tiempo ETEA ha estado dedicada a asimilar el espectacular crecimiento de las etapas anteriores.

El hecho más importante y significativo de esta etapa es la creación de la Facultad de Ciencias Empresariales en 1988. Por Decreto 254/1988 de la Junta de Andalucía de 12 de julio ${ }^{18}$ se autoriza la transformación del Colegio Universitario de Córdoba en Facultad de Ciencias Económicas y Empresariales adscrita a la Universidad de Córdoba. Como en los anteriores casos, previamente se había firmado el correspondiente convenio entre la Compañía de Jesús y la Universidad de Córdoba con fecha 2 de noviembre de 1987. La creación de la Facultad llevó consigo que la Escuela Superior de Técnica Empresarial Agrícola, dejase de ser una unidad docente con titulación privada específica, así como la desaparición del Colegio Universitario de Ciencias Empresariales, que quedó sustituido por el primer ciclo de la Facultad. ETEA quedó legalmente capacitada para impartir los títulos oficiales de Diplomado en Ciencias Empresariales, de Licenciado en Ciencias Empresariales, y de Doctor en Ciencias Empresariales.

La transformación de ETEA en Facultad de Ciencias Empresariales adscrita a la Universidad de Córdoba fue el término de un largo proceso deseado por todos, cuya culminación supuso un esfuerzo de las personas y de la Institución, y una complejidad de gestiones en el exterior que no es el momento de reproducir en sus detalles.

A partir de entonces, ETEA cuenta con una fuerza propia, que es importante. Fuerza intelectual, estructural y financiera. Ha adquirido la mayoría de edad, de forma que ya no depende de apoyos externos. Puede realizar por sí misma los proyectos académicos, científicos, sociales que ella misma decida. Se encuentra incluso en condiciones de haber intensificado y aumentado su expansión internacional hacia Latinoamérica y Europa.

${ }^{18} \mathrm{BOJA}, \mathrm{n}^{\circ} 71$, de 13-09-1988, p. 3971. 
Los años siguientes la Facultad amplía sus actividades:

1994 A finales de los 80 comienzan a impartirse estudios de doctorado; la primera tesis doctoral fue defendida en ETEA en 1994.

1996 En 1996 se comenzó a impartir la Licenciatura en Investigación y Técnicas de Mercado.

1997 Comenzó el desarrollo de estudios de postgrado con diferentes Maestrías, el primero de los cuales se tuvo a partir de enero de 1999 en Sevilla con una formación específica en Cooperación al desarrollo y Gestión de ONGD. En los años posteriores se ha ampliado la oferta en otros lugares como Granada, Córdoba y Lucena.

\subsection{La línea directriz de la historia}

Volviendo la vista atrás, y considerando en su conjunto lo que ha sido la evolución y transformación cuantitativa y cualitativa de ETEA a lo largo de estos 49 años es preciso reconocer que no ha sido la consecuencia de una planificación estratégica. La fundación de ETEA no estuvo precedida de un estudio de viabilidad, ni de un estudio del mercado universitario, ni de una planificación financiera. ETEA partió de una idea, de una voluntad de hacer algo por la transformación económica y social de Andalucía. ETEA es el fruto de una convicción, no de una planificación.

La historia de la Institución ha sido una constante adaptación a las condiciones cambiantes del entorno con el permanente deseo de cumplir en cada momento los fines fundacionales. En su nivel universitario, esta adaptación se ha realizado optando por un modelo de Institución universitaria de titularidad privada con vocación de servicio público, concretamente en la modalidad de Facultad y Escuela Universitaria adscritas a una Universidad estatal.

En el momento de la fundación el modelo no estaba concretado. Solamente se entreveía la configuración de un centro universitario que tuviera cabida en el entorno social de Andalucía. El camino para llegar a él no estaba nada claro; pero el modelo era coherente en sí mismo y coherente con la realidad circundante. Había más seguridad en la "verdad" del modelo que en los medios a emplear para conseguirlo. Con avances y retrocesos sucesivos, al final ETEA ha llegado a donde se quería que llegase. Los esfuerzos que han quedado en el camino ya no cuentan. Lo único que cuenta es que el espíritu de creatividad $v$ de combatividad que ha marcado a ETEA durante estos años. no se diluyan en los próximos. 
La ETEA de hoy se parece muy poco a la del patio de San Hipólito. Sin embargo ETEA es la misma. Simplemente ha crecido. Como un niño que se hace adulto: tiene otra estatura, otro vigor, otro aspecto, pero es la misma persona. ETEA desde su fundación adquirió un estilo de procedimientos y de toma de decisiones, configuró un esquema de relaciones humanas, tomó una posición ante la sociedad circundante, y todo eso permanece. Estos perfiles institucionales que definieron la personalidad de ETEA en su fundación, la siguen hoy definiendo con la misma validez.

ETEA ha crecido buscando el destino de su vocación histórica. Era entonces un pequeño centro de una pequeña ciudad de provincias. Sin embargo en ETEA se hablaba un lenguaje desproporcionado a su tamaño. Las ideas eran más grandes que su estructura. No tenía solidez financiera, la base legal de su estructura académica era muy débil, los recursos humanos eran muy limitados. Pero había una idea, un proyecto y una voluntad. Tuvo fe en sí misma, y ha hecho lo que se proponía.

\section{Los valores de ETEA}

Hemos seguido la historia de ETEA, su evolución externamente visible desde 1963 hasta la actualidad. Las transformaciones cuantitativas y cualitativas han sido evidentes Esta historia es la superficie de un substrato subyacente que ha sido su fundamento ideológico. Es esta ideología asumida por las personas que han llevado a cabo la historia visible de ETEA lo que ha de permanecer en el nuevo horizonte que comenzará en 2013 con la Universidad Loyola. Como decía al principio puede terminarse este curso escolar la corporeidad visible de ETEA, pero ha de permanecer en el futuro el espíritu que ha dado consistencia a ETEA a lo largo de estos 49 años.

Voy a intentar resumir este espíritu en siete valores que han orientado la actividad visible de ETEA durante estos 49 años.

\section{I. La participación}

A lo largo de estos años las decisiones se han tomado por órganos colegiados donde han estado, representados los profesores, el personal de administración y servicios, y los alumnos. Ningún grupo en ETEA, ni siquiera los jesuitas, han disfrutado de cauces de influencia privilegiados. Este modelo participativo es el que ha 
conseguido que las personas que trabajan en ETEA se hayan sentido identificados con las decisiones que se han tomado.

Tal como se expresa la Declaración Institucional de ETEA de julio 2000 en el punto 10 , la preocupación central por la persona invita a concebir la vida universitaria no sólo como un concierto de saberes, sino también como una comunidad de personas y grupos. Por ello ETEA ha asumido como modelo propio de funcionamiento la participación responsable por medio del diálogo respetuoso, en un sistema donde todas las tendencias sean escuchadas, valoradas e integradas.

\subsection{El autogobierno}

Es un hecho sobradamente conocido y aceptado, que la titularidad de ETEA es de la Compañía de Jesús. La Compañía de Jesús es la propietaria del patrimonio que usa ETEA, y la Compañía de Jesús en virtud de los propios estatutos de ETEA puede intervenir el gobierno del Centro en el momento en que lo juzgue necesario. Sin embargo no lo ha hecho nunca a lo largo de estos 49 años. Todas las decisiones de gobierno importantes se han tomado en los órganos colegiados de gobierno por mayoría de votos, y la Compañía de Jesús teniendo el derecho de invalidar estas decisiones ni lo ha hecho, ni ha juzgado que hubiera que hacerlo.

\subsection{La colaboración}

La convivencia de las personas que integran ETEA ha estado siempre presidida por un espíritu de mutua lealtad, de mutua ayuda. Lealtad y ayuda de los profesores entre sí; lealtad y ayuda de los profesores con los estudiantes; lealtad y ayuda del personal administrativo con los profesores y con los estudiantes. El personal de administración y servicios ha tenido siempre voluntad para resolver los asuntos. El profesorado además de la seriedad profesional y dedicación personal a su horario de clases, ha atendido a los alumnos en sus despachos. incluso en sus propios domicilios. Cualquier profesor puede contar con la ayuda de sus compañeros para sustituirlo en algún examen, para ayudarle en la preparación de una clase, o en la realización de un trabajo de investigación. Jamás en la historia de ETEA se ha producido una intriga contra nadie. El que un grupo de personas sometido a la presión de trabajo a que está sometido el personal de ETEA haya conservado este modo de proceder es el activo de más valor que tenemos en nuestro balance. Y es precisamente por esto por lo que me siento orgulloso y absolutamente gratificado de haber formado parte de ETEA. 


\subsection{Prestación de un servicio público}

ETEA, como es de todos conocido, es una institución docente de titularidad privada. En la dialéctica que se debate actualmente entre enseñanza pública y privada, ETEA está situada en el marco jurídico de la enseñanza privada. Desde este marco jurídico de la titularidad privada tomó desde un principio la opción de prestar un servicio público. Este carácter de servicio público se ha verificado en dos aspectos: el económico y el ideológico.

En lo que se refiere al aspecto económico, dado que ETEA no cuenta en sus presupuestos con ninguna financiación pública, se financia exclusivamente por las tasas académicas que pagan los estudiantes. Estas tasas son superiores a las que pagan los estudiantes de las universidades públicas.

Los estudiantes de las universidades públicas pagan un $15 \%$ del coste de la enseñanza, y el Estado cubre el $85 \%$. Con las subidas anunciadas por el Ministerio de Educación para este año el estudiante pagará en adelante el $25 \%$ y el Estado cubrirá el $75 \%{ }^{19}$.

En el caso de ETEA el estudiante debe pagar el coste total de la enseñanza. Por este motivo hay familias cuyo nivel de ingresos no les permite pagar esta cantidad. ETEA ha mantenido siempre el principio de que nadie se vea excluido de ingresar en ella por motivos económicos. Para realizar este principio se establecieron becas totales o parciales en función del nivel de renta familiar. Además se instituyeron los préstamos al honor. El estudiante no pagaba la totalidad o parte de las tasas durante la época de estudios, y reembolsaría el importe adeudado al finalizar la carrera y una vez obtenido un puesto de trabajo.

En lo que se refiere al aspecto ideológico no se ha establecido ningún filtro a la posición ideológica del profesorado, ya sea en sus posiciones políticas o religiosas. Siendo ETEA una institución de carácter confesional ha contratado sin ninguna objeción profesores tanto creyentes como no creyentes. En ETEA se procura fomentar y alimentar la fe cristiana desde una actitud absolutamente tolerante con cualquier otra opción personal.

\footnotetext{
19 http://www.publico.es/espana/430067/educacion-subira-el-precio-de-la-matricula-universita-
} ria-a-los-alumnos 


\subsection{Cooperación con el Tercer Mundo}

La cooperación de ETEA con el Tercer Mundo comenzó en 1983 desarrollado un programa de colaboración universitaria con universidades latinoamericanas. Con la Universidad Centro Americana (UCA) de San Salvador desde 1983, con la Universidad Centro Americana (UCA) de Managua desde 1986, con la Facultad de Economía de La Habana desde 1996, con la Universidad Rafael Landívar de Guatemala desde 1998. En esos años la cooperación de ETEA con Universidades Centroamericanas y del Caribe fue muy intensa. Más de 50 profesores latinoamericanos han venido a estudiar su doctorado y cursos de postgrado en ETEA. Mas de 40 profesores e investigadores de ETEA han viajado a países de America Latina o Asia ${ }^{20}$.

El crecimiento de las actividades de cooperación llegó a desbordar ampliamente lo que fueron los primeros proyectos. Así fue como en 2002 se creó la Fundación ETEA para la Cooperación y el Desarrollo. Sus programas se han extendido a Cuba, Nicaragua, Guatemala, El Salvador, Honduras, Paraguay, Ecuador, Venezuela, Uruguay, Vietnam, Camboya y Timor.

\subsection{La creación de pensamiento}

La Declaración Institucional de ETEA de julio 2000 expone este valor de la actividad intelectual de ETEA, inserta en el contexto social en el que está situada, y en contacto con ella. ETEA no puede estar al margen de los cambios sociales y económicos de la sociedad, debe ser fiel a su tiempo dando respuestas a las nuevas necesidades y retos.

La investigación ha de ser un medio al servicio de la búsqueda crítica de la verdad desde la libertad de las personas, que se inspirará en los principios de preocupación ética, servicio a la sociedad, interdisciplinariedad y búsqueda de la calidad.

Su objetivo debe ser incidir en los cambios de las estructuras sociales y culturales, con especial preocupación por la promoción de la justicia. Así como mantener un compromiso especial con el mundo rural y con el entorno andaluz.

La Revista Fomento Social, que había sido fundada por los jesuitas españoles en 1941, y de cuya dirección y edición se hizo cargo ETEA en 1991 es un instrumento importante de llevar a cabo este valor institucional.

${ }^{20}$ Página web de la Fundación ETEA para el desarrollo http://dev.ico.org/event_pdfs/forum/ETEA.pdf 


\subsection{La confesionalidad}

ETEA es un Centro Universitario de la Compañía de Jesús y, por consiguiente, es un centro confesional católico. En el aspecto confesional no hemos puesto el acento en símbolos decorativos ni en prácticas externas. La confesionalidad cristiana de ETEA se ha procurado manifestarla en la apreciación de los valores cristianos fundamentales: la libertad, la igualdad. el respeto a la persona, el servicio al hombre. En esto ha consistido la especificidad del carácter confesional de ETEA. Ha sido un acierto histórico el hecho de que el testimonio de la prevalencia de lo sobrenatural sobre lo material se haya puesto de manifiesto, más que en la exhibición de símbolos religiosos, en las relaciones humanas entre las personas, y en la presencia de valores éticos y de justicia tanto en la enseñanza como en la investigación.

\section{Apéndice: ETEA, una institución de la Compañía de Jesús}

Como justificación y explicación de lo que ha sido ETEA durante estos 49 años puede ser procedente exponer las razones por las que la Compañía de Jesús crea centros universitarios, y lo que espera de ellos. Nos pueden servir de guía para este fin tres documentos de autoridad universal en toda la Compañía de Jesús:

- El discurso del P. General Peter-Hans Kolvenbach en ETEA en 1994.

- Los decretos de la Congregación General 34 en 1995.

- El discurso del P. General Adolfo Nicolas Pachón en ESADE en 2008.

\section{El discurso del P. General Peter-Hans Kolvenbach en ETEA (I994)}

El 22 de febrero de 1994 El P. General de la Compañía de Jesús Peter-Hans Kolvenbach visitó ETEA. Durante esta visita pronunció un discurso con el título Presente y futuro de INSA$E T E A^{21}$. Recojo algunos de los párrafos de este discurso, donde el P. General expresa lo que la Compañía de Jesús piensa sobre los Centros Universitarios, y las recomendaciones que hace a ETEA.

Ninguno [de los centros] debe considerarse aislado, y como abandonado a sí mismo, sino que todos deben considerarse conectados con todos los demás y como solidarios de su suerte.

${ }^{21}$ Peter-Hans KovenBACH (2008) Discursos Universitarios, Madrid, UNIJES, 140-151 (aquí pp. 143, 144,146 y 1511 . 
[INSA-ETEA] nace con un pronunciado sentido de servicio específico a las necesidades específicas de la región; rasgo caracterizador que ha mantenido a lo largo de su historia tanto en la docencia como en la investigación, aun cuando haya tenido que acomodar sus planes de enseñanza a las exigencias legales para que sus títulos pudieran ser homologados. INSA-ETEA recogía así la orientación social que los centros educativos de la Compañía, especialmente los de educación superior, deseaban desde siempre: traducir en expresiones concretas (...) lo que después llamaríamos la opción preferencial por los pobres.

No se puede olvidar el alto grado de fe en sí misma de que INSA-ETEA ha dado pruebas. Es preciso recogerlo y felicitar por ello a la institución y a quienes la han dirigido y sostenido.

La institución, por tanto, se confiesa tributaria de la ética cristiana y, consiguientemente, de la visión del hombre y de los valores que le es propia. Más concretamente, como institución propia de la Compañía de Jesús, INSA-ETEA, se concibe como un medio para la realización de la misión de ésta tal como hoy se concibe: el servicio de la fe y la promoción de la justicia, que implica una opción preferencial por los pobres.

\section{Los decretos de la Congregación General $34(1995)^{22}$}

En las Universidades y a través de ellas tienen lugar importantes debates sobre la ética, los derroteros de la economía y la política, el sentido mismo de la vida humana. ( $\left.n^{\circ} 2\right)$

Esto significa la participación genuina de toda Universidad autodenominada jesuítica, o de toda Universidad que funcione bajo nuestra última responsabilidad, en la identidad y misión fundamentales de la Compañía. El adjetivo jesuítica requiere de la Universidad armonía con las exigencias de servicio de la fe y promoción de la justicia. $\left(n^{\circ} 7\right)$

\section{El discurso del P. General Adolfo Nicolás Pachón en ESADE (2008) ${ }^{23}$}

La internacionalización es sin duda una necesidad de supervivencia y desarrollo de un centro universitario en la era de internet y de los transportes rápidos, pero es también una llamada que todas las universidades vinculadas a la Compañía de Jesús deben atender de aunar los recursos mundiales al servicio del desarrollo humano y de promover un diálogo profundo entre culturas.

Puede suceder que se investiguen cosas útiles pero sólo para ciertos grupos sociales o que la investigación inmediatamente práctica pase por delante de la que aborda problemas

22 La Congregaciòn 34 (PP. 329 y 344). CONGREGACIÓN GENERAL 34 DE LA COMPAÑÍA DE JESÚS, Decreto sobre la Compañía y la vida universitaria, n. 7. 4 lbid., n. 6. - La Congregación 35 Decreto 2, n $39 \mathrm{III}$, p. 134

23 "Misión y Universidad: ¿Qué futuro queremos?" http://www.slideshare.net/villamarcos/ mision-y-universidad 
fundamentales de la economía, las empresas y la justicia. La creación de Institutos de Investigación especializados en la innovación social y en las administraciones públicas muestra vuestro empeño por detectar los problemas clave de la gobernanza de un mundo complejo. En definitiva, para ser coherentes con los valores proclamados, no podéis ver en la investigación sólo un instrumento de prestigio y de supervivencia, sino sobre todo el trabajo que permite decir una palabra autorizada en los foros y debates realmente importantes del mundo económico y jurídico: los que repercuten en el desarrollo humano para todos.

La investigación, como antes he subrayado, ha de pretender no sólo resolver los problemas del corto plazo sino también colaborar a la solución de los grandes problemas que afectan actualmente a la humanidad: el desarrollo sostenible y justo, la convivencia intercultural, los valores que dan sentido a la acción transformadora de la sociedad.

$Y$ en medio de esta complejidad, puede abrirse paso una sencilla forma de "utilitas", que es el servicio. Formar personas en la "utilitas", formar personas "útiles", es quizás formar servidores. No formar a los mejores del mundo, sino formar a los mejores para el mundo. Con lo que la excelencia de un profesional se mide ante todo con el parámetro del mayor servicio a la familia humana.

La promoción de la justicia es una dimensión de la misión de los jesuitas que se explicitó especialmente a partir de la Congregación General 32. Es responsabilidad de un centro como ESADE no separar la creación de riqueza de su justa distribución. Se trata de superar la división del saber que permite despreocuparse de la repercusión social y humana del funcionamiento de las empresas en el mercado. Hoy en día las grandes empresas hablan de "responsabilidad social". La responsabilidad social más importante de un centro universitario como ESADE es ser promotor de justicia a todos los niveles: en las relaciones individuales, en las organizaciones y también en las sociedades donde operan, con una visión a la vez local y global.

Hombres y mujeres, creyentes y no creyentes, creyentes de distintas confesiones religiosas colaboran en las universidades jesuitas de todo el mundo. Y lo hacen desde perspectivas diversas. Para unos es un compromiso profesional. Otros se identifican a fondo con la Misión compartida en los centros universitarios jesuitas (como UNIJES). Para otros, esta misión es vivida desde una experiencia creyente. En todo caso, lo importante es que nos sentimos comprometidos con una gran causa común ${ }^{24}$ :

\section{Declaración institucional de ETEA (2000)}

La Declaración Institucional de ETEA de julio del año 2000 recoge los objetivos de la Compañía de Jesús perseguidos en la fundación y desarrollo de ETEA durante estos 49 años. Esta declaración comenzó a elaborarse el 12 de febrero de 1999, en las Jornadas de Reflexión de ETEA, que reúnen anualmente a todo el personal para reflexionar sobre aspectos fundamentales de la misión de la institución. Una comisión se encargó luego de

${ }^{24}$ Adolfo Nicolás, Méjico abril 2010 wpd 
redactar el texto, que fue sometido en dos ocasiones a consulta de todo el personal a lo largo de 1999.

La declaración fue aprobada por el Consejo General de INSA-ETEA el día 14 de julio de 2000. El P. General de la Compañía de Jesús le dio su aprobación definitiva el día 14 de agosto de 2000.

Número 3. ETEA fue creada y es mantenida como instrumento para su misión: el servicio de la fe y la promoción de la justicia en un mundo de diversidad cultural y religiosa.

Número 5. Para llevar adelante este proyecto ETEA cuenta con una comunidad humana, mayoritariamente seglar, a la que los jesuitas ofrecen su herencia espiritual y apostólica, sus recursos educativos y su amistad.

Número 6. En cuanto centro universitario, ETEA aspira a ser un lugar de serena y abierta investigación y discusión de la verdad garantizando para ello la autonomía fundamental, la integridad y la sinceridad.

Número 7. ETEA tiene una vocación específica por los temas agrarios, por el mundo rural y por los estudios locales y regionales, pero con apertura a la dimensión nacional e internacional, especialmente a América Latina; se propone como objetivo fundamental la formación de personas que sean "agentes de cambio", es decir, que fomenten estructuras sociales y empresariales más justas y solidarias, más eficientes y eficaces. Facilita espacios para la explicitación de lo cristiano, ya sea a través de la reflexión teológica (diálogo de la fe con la sociedad actual y con la ciencia), ya mediante una oferta pastoral (orientada al crecimiento espiritual o a la formación de las personas, o a la celebración de la fe). 